\title{
Supporting Information \\ Dispersion of Hydrophobic Co Supracrystal in Aqueous Solution
}

\author{
Nailiang Yang ${ }^{1,2}$, Zhijie Yang ${ }^{1,2}$, Marie Held ${ }^{3}$, Pierre Bonville ${ }^{4}$, Pierre-Antoine \\ Albouy ${ }^{5}$, Raphaël Lévy ${ }^{3}$, Marie-Paule Pileni*1,2,4 \\ ${ }^{1}$ Sorbonne Universités, UPMC Univ Paris 06, UMR 8233, MONARIS, F-75005, Paris, France \\ ${ }^{2}$ CNRS, UMR 8233, MONARIS, F-75005, Paris, France \\ ${ }^{3}$ Institute of Integrative Biology, University of Liverpool, Crown Street, L69 7ZB Liverpool, United \\ Kingdom \\ ${ }^{4}$ CEA/IRAMIS, CEA Saclay, 91191, Gif-sur-Yvette, France \\ ${ }^{5}$ CNRS, UMR 8502 Laboratoire de Physique des Solides, Université Paris-Sud, 91405 Orsay, France
}

Table S1. Effect of concentration and ultrasonic treatment on the stability of the system.

\begin{tabular}{|c|c|c|c|c|}
\hline \multirow{2}{*}{$\begin{array}{l}\text { Concentration } \\
\text { of } \operatorname{PPD}(\mu \mathrm{M})\end{array}$} & \multirow{2}{*}{$\begin{array}{c}\text { Amount of } \\
\text { Supracrystals } \\
(\mathrm{mg} / \mathrm{mL})\end{array}$} & \multirow{2}{*}{$\begin{array}{l}\text { Ultrasonic } \\
\text { treatment }\end{array}$} & \multicolumn{2}{|c|}{ Duration } \\
\hline & & & $\begin{array}{c}\text { Precipitate } \\
\text { appear }\end{array}$ & $\begin{array}{c}\text { Precipitate } \\
\text { totally }\end{array}$ \\
\hline 15 & 2 & No & $10 \mathrm{~min}$ & $25 \mathrm{~min}$ \\
\hline 15 & 2 & Yes & $5 \mathrm{~min}$ & $15 \mathrm{~min}$ \\
\hline 30 & 2 & No & $90 \min$ & $150 \mathrm{~min}$ \\
\hline 30 & 2 & Yes & $15 \mathrm{~min}$ & $50 \mathrm{~min}$ \\
\hline 60 & 2 & No & $>12 \mathrm{~h}$ & -- \\
\hline 60 & 4 & No & $12 \mathrm{~h}$ & -- \\
\hline
\end{tabular}



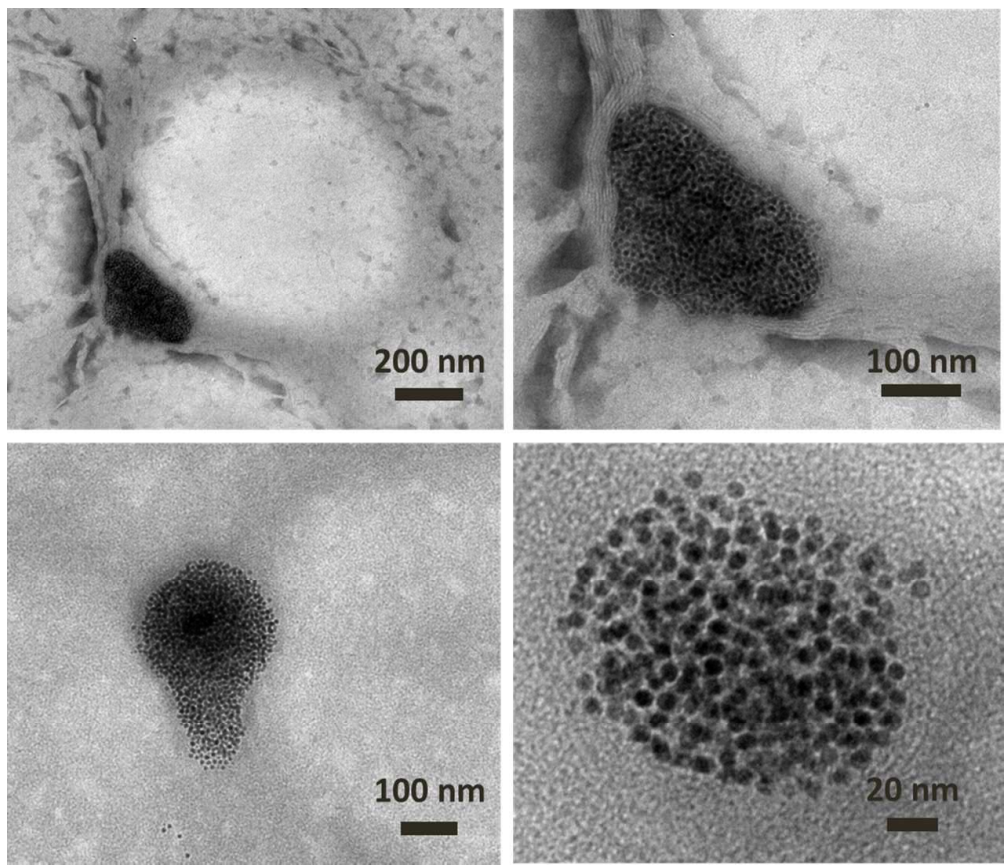

Figure S1. Supracrystals have been destroyed when a high chloroform ratio (larger than $50 \%$ percent in chloroform + ethanol solution) at the first stage.
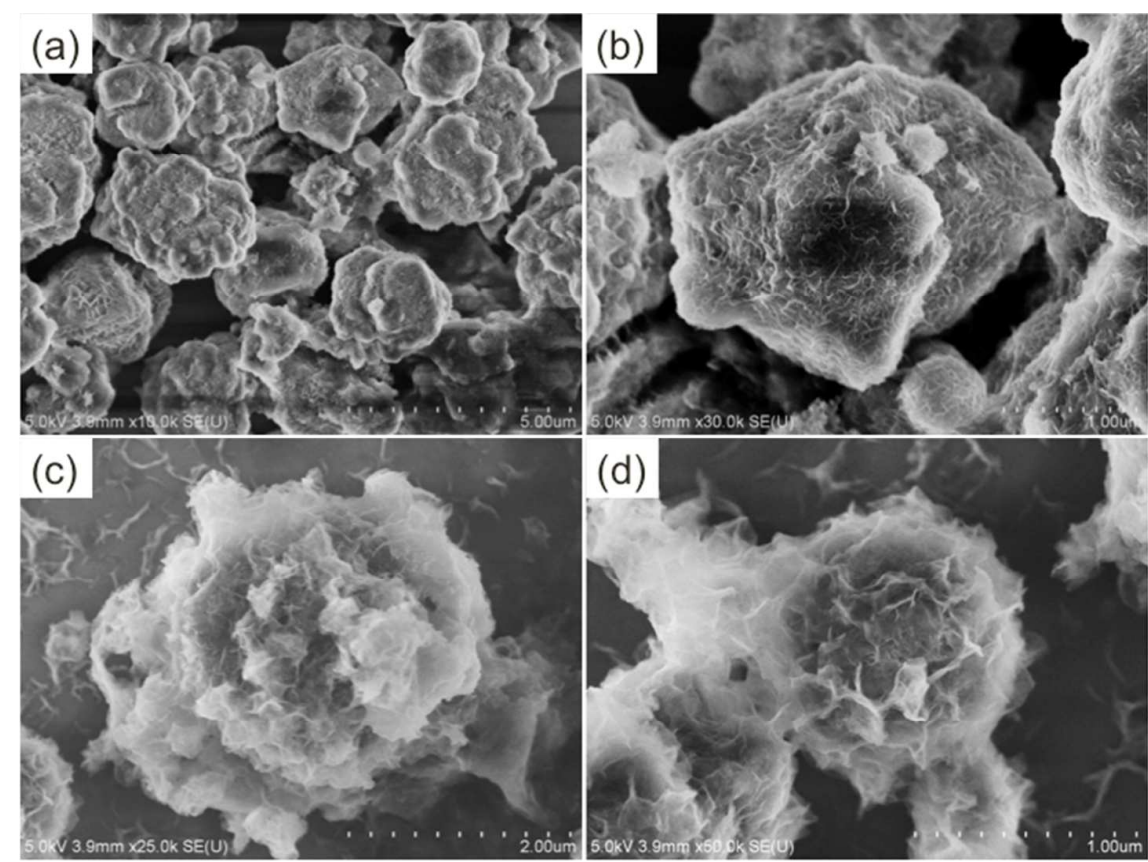

Figure S2. Morphology of supracrystal-vesicles composite. The surface of the supracrystals become rough with some silk-like organic coating. 

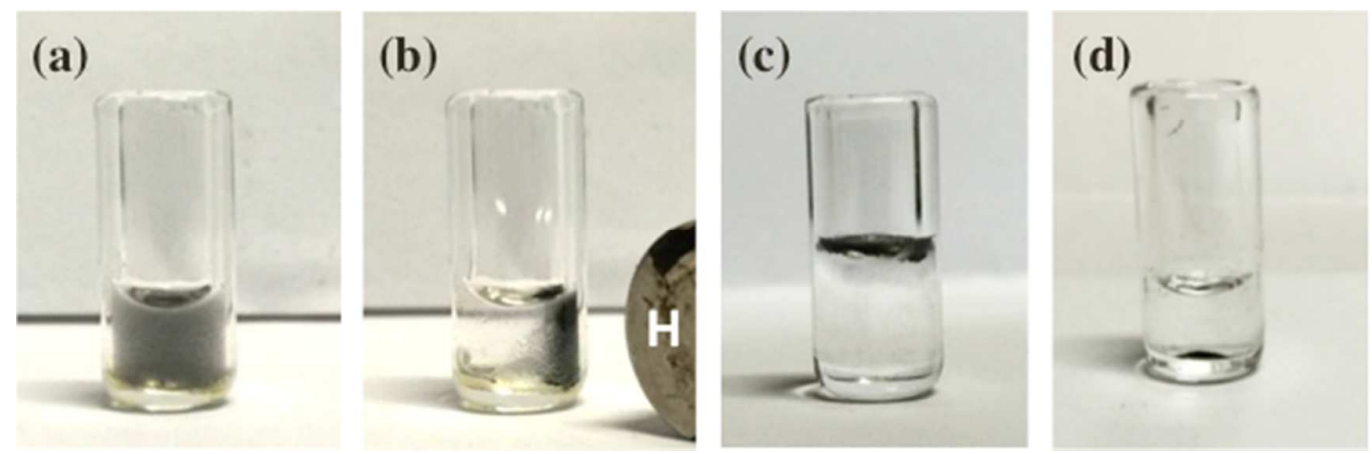

Figure S3. (a) The supracrystal-vesicles composite can be well dispersed in water and (b) can be operated by a magnetic field. (c) shows the composite can float on the interface of chloroform while (d) the naked supracrystals cannot.
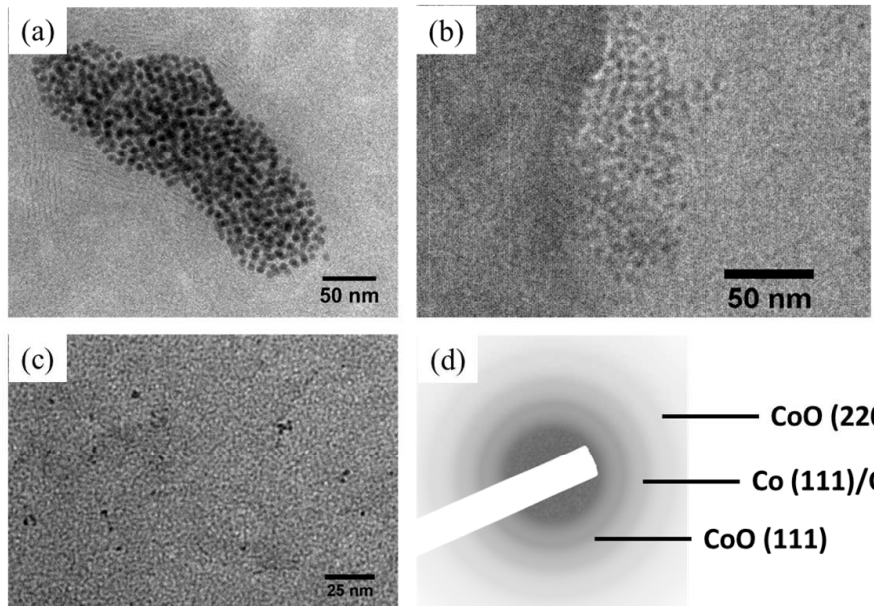

(d)

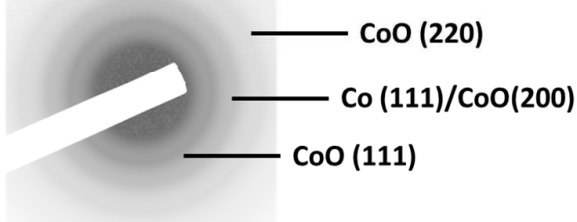

Figure S4. TEM images and SAED for corresponding nanoparticles.

The corresponding nanoparticles display two phenomena, some will aggregate to form some small amorphous assembly because of the hydrophobic aggregate (Figure S4a). These small assemblies are surrounded by lipid bilayers. But it is clear it has been oxidized to some extent, which can be seen from the electron diffraction. There is a diffraction ring corresponding to $\mathrm{CoO}$. The reason for this ring is not so clear because the oxidation takes place at room temperature, which will not result in a strong crystallization. Meanwhile, some particles with very low contrast or even fragments can be observed under TEM (Figure S4b, c), which is due to the high oxidation of the separated nanoparticles. 